\title{
LAGUNAS DEL DERECHO Y POSITIVISMO JURÍDICO \\ Un examen de la concepción de las lagunas de C. Alchourrón y E. Bulygin*
}

\author{
José Antonio Ramos Pascua *** \\ Universidad de Salamanca \\ ascua@usal.es
}

\begin{abstract}
RESUMEN. En este artículo se hace un recorrido por la cambiante actitud del positivismo jurídico frente al problema de las lagunas del Derecho, cuya existencia negó inicialmente, pero que finalmente reconoció, confiando su integración a la discrecionalidad judicial. Especial atención y valoración crítica se dedica a una de las más influyentes doctrinas positivistas sobre las lagunas, la defendida por C. AlChOURRón y E. BULYGIN en Normative systems. Se discute aquí, entre otras cosas, su distinción entre lagunas de conocimiento y de reconocimiento, normativas y axiológicas, y sus implicaciones en la concepción positivista del Derecho como sistema de normas autosuficiente e independiente de la moral.
\end{abstract}

Palabras clave: lagunas del Derecho, positivismo jurídico, discrecionalidad judicial, lagunas axiológicas, sistema jurídico.

\section{Legal Gaps and Legal Positivism.}

\section{AlChourrón and E. Bulygin's Conception of Gaps under Examen}

ABSTRACT. This article conducts an analysis on the variant attitude of legal positivism towards legal gaps, whose existence initially denied, but finally recognised, entrusting their integration to judicial discretion. Special attention and critical assessment is devoted to one of the most influential positivist theories about legal gaps, the one defended by C. ALCHOURRón and E. BULYGIN in Normative Systems. Their distinction between knowledge and recognition gaps, and between normative and axiological gaps is discussed, as well as their implications in the positivist conception of the law as a self-sufficient system of norms, independent of morals.

Keywords: legal gaps, legal positivism, judicial discretion, axiological gaps, legal system.

\footnotetext{
* Fecha de recepción: 16 de junio de 2016. Fecha de aceptación: 16 de febrero de 2017.

Este trabajo se inserta en el Proyecto de Investigación DER2016-74898-C2-1-R, financiado por el Ministerio de Economía y Competitividad, AEI y FEDER.

*** Facultad de Derecho, Paseo de F. Tomás y Valiente, s/n, 37007, Salamanca.
} 


\section{INTRODUCCIÓN}

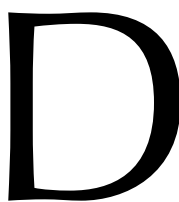

esde siempre se ha sabido que el Derecho positivo no puede tener prevista una solución específica para todos los innumerables conflictos jurídicos que las relaciones sociales, plagadas de intereses contrapuestos, provoquen en el futuro. Esta idea sobre los límites de las previsiones de cualquier legislador es casi un tópico del pensamiento jurídico. Es forzoso aceptar que en la práctica del Derecho surgirán controversias o casos nuevos, derivados de nuevas realidades vinculadas, por ejemplo, a los avances científicos y tecnológicos que pueden transformar la vida social. Baste pensar en los avances que se han venido produciendo en los últimos tiempos en el campo de la biotecnología, abriendo posibilidades de actuación humana previamente impensables y que obviamente el Derecho no regulaba, tales como la gestación subrogada o la manipulación genética con fines eugenésicos.

Más frecuentes son los casos subsumibles en supuestos de hecho que el Derecho positivo regula en términos generales, pero que presentan peculiaridades, propiedades o circunstancias particulares dignas de ser tomadas en consideración, y, sin embargo, no contempladas por el legislador. Se trata de lagunas especialmente problemáticas porque están enmascaradas, en la medida en que el Derecho impone una consecuencia jurídica al supuesto de hecho general del que el caso es una manifestación concreta. Pero esa solución es insatisfactoria porque hay buenas razones para suponer que si el legislador hubiera previsto la particularidad del caso, habría introducido una excepción a la consecuencia jurídica prevista en general para los de su mismo género. Hay quien denomina lagunas axiológicas a estas lagunas especialmente problemáticas, que, por cierto, son muy frecuentes en la práctica jurídica. Hasta el punto de que puede afirmarse que, si no todas, la mayor parte de las lagunas son axiológicas, porque su identificación como tales lagunas remite al sistema valorativo inherente al Derecho.

En realidad, las lagunas que parecen evidentes, como por ejemplo la que existió cuando ninguna ley regulaba la gestación subrogada a pesar de que ya era técnicamente viable y comenzaba a practicarse, también son problemáticas, porque siempre cabe alegar que si el Derecho no regula una conducta o actividad es porque no la considera relevante $\mathrm{y}$, por tanto, la deja fuera de su radio de acción, reconociéndola así como libre, permitida, o, al menos, no prohibida. Como veremos, esta argumentación fue durante mucho tiempo uno de los principales recursos en la estrategia de cierto sector del positivismo jurídico para zanjar el incómodo problema de las lagunas, que amenazaba uno de sus dogmas más preciados: el de la plenitud hermética del Derecho ${ }^{1}$.

Una prueba evidente de que el problema de las lagunas siempre ha estado presente en la mente de los juristas se puede extraer de la existencia, frecuente en todas las

${ }^{1}$ El dogma de la plenitud, normalmente atribuido al positivismo legalista, tuvo en realidad su origen en el iusnaturalismo moderno, que intentó construir deductivamente, a partir de ciertos principios racionalmente válidos, un sistema completo de normas capaz de ofrecer solución para cualquier problema jurídico. Este ideal se tradujo históricamente en la codificación del Derecho positivo, que a su vez dio lugar a la aparición de algunas de las primeras corrientes positivistas, como la francesa Escuela de la exégesis. No es exagerado afirmar, en consecuencia, que el positivismo legalista fue una especie de hijo rebelde del iusnaturalismo ilustrado. Sobre el proceso de formación y desarrollo del dogma de la plenitud o compleción del Derecho, vid. M. A. RoDiLLA, Teoría del Derecho, Salamanca, Ratio Legis, 2013, 348 y ss. 
épocas y sistemas jurídicos, de órdenes de prelación de fuentes de Derecho aplicables. Cuando el legislador dispone que en los casos no previstos por sus leyes se aplique, por ejemplo, la costumbre, o el Derecho romano, o el canónico, o la equidad, o los principios del Derecho natural, está admitiendo de forma implícita la previsible existencia de lagunas en su legislación ${ }^{2}$. Una realidad tan obvia como la inevitabilidad de las lagunas del Derecho, que apenas mereció comentarios doctrinales durante siglos, se convirtió en cuestión fuertemente polémica a finales del siglo XIX y principios del XX, coincidiendo con el predominio del positivismo jurídico legalista.

\section{EL PROBLEMA DE LAS LAGUNAS EN LA TRAYECTORIA HISTÓRICA DEL POSITIVISMO JURÍDICO}

Esta proteica corriente de pensamiento fue, al menos en sus orígenes, decididamente estatalista, identificando el Derecho con la ley, entendida como expresión de la voluntad del poder político soberano en un Estado. El positivismo legalista no estaba dispuesto a poner límites a la voluntad de las autoridades del Estado reconociendo validez a otras fuentes incontrolables del Derecho, y menos aún si estas se presentaban en forma de etéreas leyes naturales o inseguros principios morales con pretensiones de validez universal o simplemente social. La defensa de esa concepción del Derecho como un bloque o sistema de normas autosuficiente, independiente y cerrado a la invasión de cualquier otro sistema normativo, empujó a un sector relevante de autores positivistas a postular el dogma de la plenitud hermética del Derecho, que implicaba, entre otras cosas, la negación de las lagunas. Si el Derecho era un sistema cerrado de normas no podía tener lagunas, porque si las tuviera sería difícil demostrar su independencia frente a aquellos otros órdenes normativos, como la moral, a los que sería casi inevitable acudir para rellenarlas ${ }^{3}$. Admitir la existencia de lagunas sería tanto como reconocer que el espléndido aislamiento del Derecho postulado por el positivismo legalista no era más que una ficción interesada tendente a asegurar el monopolio del control social por parte del poder político del Estado.

No era fácil demostrar, frente a la realidad evidente de casos no previstos por el Derecho legislado, la inexistencia de lagunas en el mismo. Fue necesario un apreciable

2 F. Tomás y VALIEnTE, Manual de historia del Derecho español, Madrid, Tecnos, 2012, 4. a ed., 150, advierte, por ejemplo, en relación con los fueros extensos de la Edad Media, que «no todos los problemas reales podían estar resueltos por el fuero, a pesar de pretenderlo así quienes lo redactaron». De ahí que algunos fueros se remitieran al albedrío del juez para resolver los casos no previstos. Otros, como el de Soria, preveían el nombramiento de una comisión de cuatro caballeros para que buscaran una solución justa para el caso, solución que se añadiría al fuero para resolver otros casos futuros semejantes. A pesar de esa conciencia, presente en todas las épocas, de la insuficiencia previsible del Derecho positivo, como observa J. GILISSEN, «Le problème des lacunes du droit dans l'évolution du droit médiéval et moderne», en Ch. PERELMAN (ed.), Le problème des lacunes en droit, Bruxelles, E. Bruylant, 1968, 197, el problema de las lagunas apenas ha sido estudiado por los historiadores del Derecho, porque solo comienza a plantear dificultades reales a partir del siglo XIX, es decir, a partir del momento en que se desarrolla la teoría de la necesaria plenitud del Derecho positivo.

3 Cfr. N. BobBio, Teoría general del Derecho, trad. por E. Rozo, Bogotá, Temis, 1987, 212, para quien admitir la existencia de lagunas sería tanto como admitir que los jueces tendrían que recurrir a fuentes jurídicas extraestatales, como la costumbre, la equidad, la naturaleza de las cosas, etc., y eso amenazaría la omnipotencia jurídica del Estado. Por eso, la concepción del Derecho como orden completo de normas representa el punto central («il cuore del cuore») del positivismo jurídico (N. BoBBIO, Il positivismo giuridico, Torino, Giappichelli, 1979, 244). 
derroche de ingenio para conseguirlo. Son bien conocidas las principales doctrinas con las que se defendió la concepción del Derecho como un sistema de normas completo y carente de lagunas: la doctrina del espacio vacío de Derecho y la de la norma general exclusiva, norma negativa, o norma de clausura ${ }^{4}$.

La primera doctrina, expuesta, entre otros, por K. BERGBOHM, uno de los positivistas más conocidos del siglo XIX, y por S. ROMANO5 ${ }^{5}$ ya en el siglo XX, parte del supuesto de que el Derecho no regula ni pretende regular todos los casos imaginables. Pues bien, aquellos hechos, actos o relaciones que deja sin regular deben considerarse irrelevantes jurídicamente, puesto que quedan fuera de los límites de su ordenamiento. Los deberes que conlleva la amistad, por ejemplo, no vienen impuestos por nuestro ordenamiento jurídico, pero eso no constituye una laguna del mismo. Supongamos que se plantea ante los tribunales un conflicto sobre tal materia irrelevante o indiferente para el Derecho español: por ejemplo, que una persona demanda a un amigo y le exige una indemnización por el daño moral que le hizo sufrir al no recibir su felicitación de cumpleaños. En tal caso, el juez simplemente tendría que desestimar la demanda.

La existencia de materias irrelevantes para un determinado sistema jurídico puede admitirse sin dificultad. Lo inadmisible es la afirmación de que todos los casos no previstos por él pertenecen al espacio vacío de Derecho y son, por tanto, irrelevantes. Habrá materias que el Derecho en cuestión no regule ni pretenda regular, en cuyo caso no existiría verdadera laguna, y otras que no regule pero que deba regular, porque sean relevantes jurídicamente. Serán casos respecto a los cuales exista una fundada expectativa o exigencia de regulación jurídica, derivada del conocimiento de los fines, principios y valores plasmados en las normas jurídicas y en los que se evidencie la voluntad del legislador. Estos casos cuya regulación es justificadamente esperable o fundadamente exigible, porque resulta necesaria para que se realice plena y congruentemente la voluntad del legislador o el espíritu de la ley, son los que ponen en evidencia la existencia de lagunas en el Derecho; lagunas que son perfectamente compatibles con la existencia de espacios jurídicamente irrelevantes.

La segunda doctrina, la de la norma de clausura, que es similar pero no idéntica a la primera, fue propuesta por E. ZITELMANN, quizá el primer autor que dedicó un estudio monográfico al problema de las lagunas, y posteriormente desarrollada por otros autores positivistas, como D. DONATI o H. KELSEN ${ }^{6}$. Actualmente está bastante desacreditada, por más que haya querido dignificarse presentando tal norma como un

4 Estas doctrinas representan la reacción del positivismo legalista en defensa de la tesis de «la plenitud hermética del ordenamiento jurídico», como denomina C. CossIO, La plenitud del ordenamiento jurídico, Buenos Aires, Losada, 1947, 23, a la que todavía representa para él una «magna conquista del pensamiento iusfilosófico contemporáneo». Como explica M. A. RoDILla, Teoría del Derecho, op. cit., 358 y ss., en su transparente exposición y crítica de dichas doctrinas, su formulación fue la respuesta a los ataques que dirigieron contra aquella tesis, a finales del siglo XIX y comienzos del XX, movimientos tales como el del Derecho libre, la Jurisprudencia de intereses o la Escuela de la investigación científica del Derecho, que abrieron una puerta trasera a la irrupción del Derecho natural, con el consiguiente peligro de arbitrariedad judicial e inseguridad jurídica.

5 Vid. K. BergbOHM, Jurisprudenz und Rechtsphilosophie, Leipzig, 1892; S. Romano, Osservazioni sulla completezza dell'ordinamento statale, Modena, 1925.

6 E. Zitelmann, Lücken im Recht, Leipzig, Duncker \& Humblot, 1903; D. Donati, Il problema delle lacune dell'ordinamento giuridico, Milano, 1910; H. KELSEN, Teoría pura del Derecho, trad. de la 1. a ed. de 1934 a cargo de G. Robles y F. F. SÁnChEZ, Madrid, Trotta, 2011, 107 y ss. En la edición definitiva de 1960 de la Reine Rechtlebre (trad. por R. J. VERNENGO, México, UNAM, 1982, 254 y ss.), KELSEN evita referirse a la existencia 
principio de libertad que cierra el sistema jurídico frente a cualquier restricción no explícita de la conducta. En opinión de los autores que defienden esta doctrina, un hecho solo tiene consecuencias jurídicas si el Derecho se las atribuye. Luego, todo aquello que el Derecho no regule no tendrá consecuencias jurídicas y podrá realizarse o no realizarse libremente. Como esto parece de pura lógica, de ahí deducen los autores citados que existe en cualquier sistema jurídico una norma complementaria implícita conforme a la cual lo no prohibido (ni exigido) por las normas jurídicas vigentes está permitido, y en consecuencia el juez habrá de desestimar las demandas de quienes exijan su realización o su omisión.

Es cierto que alguna regla de clausura puede estar vigente en un determinado orden jurídico o sector del mismo, que en ese caso en principio no tendría lagunas. Se ha observado, con razón, que el principio de legalidad penal, nullum crimen sine lege, funciona en el ámbito del Derecho penal como regla de clausura o norma general exclusiva, porque viene a significar que todas aquellas conductas que la ley no prohíba como delictivas deben considerarse lícitas. En realidad esto no significa que en el Derecho penal las lagunas sean imposibles. Imaginemos que una reforma del Código penal introdujera un nuevo delito, pero no precisara la pena correspondiente a quien lo cometiera. En tal caso, existiría una laguna técnica evidente.

En definitiva, el principio de legalidad penal excluye lagunas, pero no las excluye todas. Por otra parte, se trata de un principio del llamado Estado de Derecho, característico de las democracias liberales, que no está presente en todos los sistemas jurídicos, aunque seguramente debería estarlo. Aparte de no ser extensible a todos los sistemas jurídicos, el principio de legalidad penal tampoco es extensible a todo el ordenamiento. En el ámbito del Derecho civil, por ejemplo, el recurso a la analogía, excluido del Derecho penal, se emplea con frecuencia, y puede tener como consecuencia que conductas no expresamente prohibidas ni exigidas por la ley resulten prohibidas o exigidas por la aplicación analógica de alguna norma reguladora de un caso similar al no regulado. Más aún, en el Derecho administrativo, al menos en los ordenamientos jurídicos liberales, suele regir un principio contrario al de la norma general exclusiva en lo referente a las atribuciones o facultades de los funcionarios públicos. En este ámbito, no suele ser verdad que lo no prohibido esté permitido, sino todo lo contrario. Aquello que el Derecho no permite expresamente a los funcionarios en el ejercicio de sus funciones debe considerarse prohibido para ellos. Su actividad normalmente está sujeta a un régimen de prerrogativas expresas. En esa interdicción de la arbitrariedad se traduce aquí el principio de legalidad o imperio de la ley; exigencia de seguridad jurídica y de justicia que, por cierto, como sostendré más adelante, también debe considerarse extensible a los jueces y su supuestamente inevitable discrecionalidad frente a las lagunas del Derecho.

Se ha observado también que la doctrina de la regla de clausura juega con la ambigüedad del término «permitido» en las proposiciones normativas ${ }^{7}$. Permitido puede

de una norma general exclusiva, pero eso no significa que abandone la idea de fondo. Vid., al respecto, J. RuIZ MANERO, Jurisdicción y normas, Madrid, C. E. Constitucionales, 1990, 40 y ss.

7 Cfr. G. vON Wright, Norma y acción, trad. por P. G. ${ }^{a}$ FerRero, Madrid, Tecnos, 1970, 100 y ss.; C. ALCHOURRÓn y E. BulYGin, Normative Systems, Wien/New York, Springer Verlag, 1971. Cito por la trad. de los mismos autores: Introducción a la metodología de las ciencias jurídicas y sociales, Buenos Aires, Astrea, 1974, 
significar autorizado por el Derecho en el sentido de garantizado o protegido, pero también puede significar algo de menor alcance: que un acto no esté prohibido. Quien afirme que lo no prohibido está permitido en este segundo sentido, está expresando una simple tautología. Sin embargo, quien afirme que lo no prohibido está permitido en el primer sentido, en el sentido de protegido o autorizado por el Derecho, está afirmando algo que podría ser verdadero en un determinado sistema jurídico, si existen en él normas que conceden el permiso en cuestión, pero que también podría ser falso, si tales normas permisivas no existen. Y ello porque, como ya hemos adelantado, puede ocurrir que una conducta no exigida ni prohibida por norma jurídica alguna resulte exigible o ilícita cuando le sea aplicable por analogía una norma prevista para regular conductas distintas pero semejantes en lo esencial a la primera.

Allí donde sea obligado o posible aplicar el Derecho por analogía no habrá lugar para la regla de clausura. La razón de fondo es que lo no prohibido ni exigido expresamente por la ley puede estarlo por un principio no expreso que se haga patente a través de la analogía, en cuanto que inspire otras leyes reguladoras de casos similares. En síntesis, la regla de clausura tiene un alcance limitado a aquellos sistemas jurídicos o sectores del Derecho en los que dicha regla se haya dictado válidamente, y por tanto no excluye la existencia de lagunas en general, pues no es verdad que esté implícita en todo Derecho.

No fueron los anteriores los únicos argumentos esgrimidos para negar la existencia de las lagunas. Se alegó también, entre otras cosas, que estando los jueces sometidos a la prohibición de denegar justicia y teniendo el deber inexcusable de resolver todos los casos que se les presenten aplicando el sistema de fuentes establecido (como establece, por ejemplo, el art. 1.7 del CC español), es forzoso suponer que el Derecho positivo carece de lagunas, pues de lo contrario no sería posible que los jueces cumplieran ese deber como de hecho lo cumplen ${ }^{8}$. Este argumento, o el argumento de que el sistema jurídico dispone de recursos suficientes para rellenar cualquier laguna, no parece muy convincente a efectos de demostrar la inexistencia de lagunas en el Derecho. Solo demuestra que las lagunas pueden y deben ser colmadas sin que paralicen la aplicación del Derecho, pero no demuestran su inexistencia. Negar la existencia de lagunas porque existen jueces que deben resolver conforme a Derecho los casos no previstos es «lo mismo que afirmar que un traje no puede tener agujeros porque el sastre siempre puede remendarlos»?.

171 y ss., 184 y ss. y 220 y ss.; R. GUASTINI, Interpretar y argumentar, trad. por S. ÁLVAREZ, Madrid, CEPC, 2014,157 y ss.

8 U. KLUG, «Observations sur le problème des lacunes en droit», en Le problème des lacunes en droit, op. cit., 92-93, observa, frente a la idea de aquellos positivistas para quienes la prohibición de denegación de justicia garantiza la inexistencia de lagunas, que esa prohibición es solo contingente y no una exigencia lógica de todo orden jurídico.

9 Cfr. C. AlChOURRÓn y E. Bulygin, Introd. a la metodología..., op. cit., 182. En el mismo sentido se manifiesta C. LuZzATTI, La vaghezza delle norme. Un'analisi del linguaggio giuridico, Milano, Giuffrè, 1990, 413-414, para quien un vacío que no existe no necesita colmarse. Si se establecen en un Derecho medios de integración de lagunas es porque las lagunas existen. Como dice K. LARENZ, Metodología de la ciencia del Derecho, trad. por M. R. Molinero, Barcelona, Ariel, 1994, 398, negar la existencia de lagunas porque del sistema jurídico se pueden extraer nuevas normas para resolverlas es tanto como ignorar «el momento creador propio de todo desarrollo del Derecho, en especial de la integración de lagunas». Las lagunas pueden ser colmadas por el juez creando nuevas normas, pero «una norma jurídica que primero ha de ser creada, no existe todavía». También 
Pese al esfuerzo de algunos autores positivistas, empeñados en negar la existencia de lagunas con el fin de proteger su ideal de un sistema jurídico completo e independiente, que no necesitara recurrir a la ley natural ni a la moral social para integrarse, las lagunas siguieron manifestándose en la práctica jurídica con la tozudez de los hechos. El mismo Derecho positivo reconoce sus límites previendo la posible presencia de lagunas y ofreciendo soluciones. Luego, negar su existencia es casi contradictorio para un positivista. Es inevitable, en definitiva, constatar el fracaso de ese primer positivismo legalista o estatalista en su lucha quijotesca contra la posibilidad misma de que existieran lagunas, y contra sus implicaciones subversivas. Unas implicaciones que desbarataban la ficción de un Derecho estatal pleno, y que, como ya indicamos, fueron apuntadas a finales del siglo XIX y comienzos del XX por diversos autores críticos con la concepción positivista del Derecho, tales como F. GÈnY, H. KanTOROwICZ o Ph. HeCK ${ }^{10}$.

En el tema que nos ocupa, el positivismo jurídico dio un giro notable en la segunda mitad del siglo XX. Un giro que podríamos denominar «lingüístico», no ya porque tenga su origen en la obra de un destacado filósofo analítico del lenguaje como H. L. A. HART, sino porque relaciona el problema de las lagunas, más que con vacíos o ausencias de regulación, con la inevitable vaguedad o indeterminación del lenguaje en que se expresan las normas jurídicas. A diferencia del positivismo legalista continental, HART, que pertenece a una tradición positivista diferente, la Jurisprudencia analítica inglesa, iniciada por J. BENTHAM y J. AUSTIN, reconoce abiertamente la existencia en el Derecho de incontables lagunas o, mejor, indeterminaciones de límites, derivadas de la textura abierta del lenguaje jurídico. Este concepto alude al carácter inevitablemente incompleto e incierto de cualquier intento de guiar la conducta humana mediante reglas abstractas, llenas de términos genéricos ${ }^{11}$. A fin de garantizar la separación conceptual entre el Derecho y la moral exigida por el positivismo jurídico, y al mismo tiempo hacer posible la necesaria integración o compleción del Derecho, HART optará por reconocer a los jueces un cierto margen de discrecionalidad para resolver, frente a las circunstancias de cada caso, las indeterminaciones de las normas jurídicas. Esa discrecionalidad no equivale a arbitrariedad sino a buen juicio, e implica que los jueces deben apoyar sus decisiones en pautas razonables, que bien podrían ser principios morales, aunque no formen parte del Derecho ${ }^{12}$.

La admisión de la discrecionalidad judicial a fin de superar las lagunas o indeterminaciones de las normas jurídicas resultaba en principio extraña como doctrina

\footnotetext{
V. ITURRALDE SESMA, «Análisis de algunas cuestiones relativas al problema de las lagunas jurídicas», en Anuario de Filosofía del Derecho, n. e., vol. V, 1988, 362 y ss., y M. SEGURA ORTEGA, «El problema de las lagunas en el Derecho», en Anuario de Filosofía del Derecho, n. e., vol. VI, 1989, 300, critican la teoría que cifra la compleción del sistema jurídico en la obligación que tienen los jueces de resolver todos los casos. SEGURA ORTEGA observa (p. 298) que esa teoría confunde dos nociones diferentes de laguna: como ausencia de regulación para un caso y como imposibilidad de hallarle solución.

${ }_{10}$ Cfr. P. ChIASsoni, Técnicas de interpretación jurídica. Breviario para juristas, Madrid/Barcelona, Pons, 2011, 199 y ss.; M. J. García SAlgado, La jurisprudencia de intereses de Philipp Heck, Granada, Comares, 2011,180 y ss.

${ }_{11}$ Cfr. H. L. A. HaRT, El concepto de Derecho, trad. por G. R. CARRIÓ, Buenos Aires, Abeledo Perrot, 1963,155 y ss.

${ }_{12}$ Cfr. H. L. A. Hart, Essays in Jurisprudence and Philosophy, Oxford, Clarendon Press, 1983, 6 y ss., 103 y ss., 140, etc. Recientemente se ha publicado un borrador inédito de HART en el que explora la noción de discrecionalidad: «Discrecionalidad», trad. por J. R. DE PÁRAMO, en Doxa, 37 (2014), 85-98.
} 
positivista ${ }^{13}$. Hay que tener en cuenta que el positivismo de HART, a diferencia del positivismo legalista anterior, no tiene como trasfondo ideológico inmediato la defensa de una teoría del Derecho estatalista. Expresa más bien la adopción de una actitud metodológica descriptiva y no prescriptiva o valorativa en la concepción del Derecho. Es la diferencia, destacada por BoBBIO, entre el positivismo jurídico entendido como teoría estatalista del Derecho o como simple actitud descriptiva, objetiva o neutral éticamente, en la determinación del Derecho ${ }^{14}$. Por ello, no es sorprendente que HART acepte un recurso, la discrecionalidad judicial, que sería inadmisible para el viejo positivismo estatalista. Inadmisible, entre otras cosas, porque los jueces no representan la voluntad del titular de la soberanía y, en consecuencia, no están autorizados para crear Derecho. Otra explicación puede encontrarse en la práctica jurídica del Common law con la que HART está familiarizado, y en la que los jueces tienen un papel más decisivo o creativo que en los sistemas jurídicos de tipo romano-germánico.

Una aportación muy destacable a la concepción positivista de las lagunas del Derecho es la representada por la obra de C. ALCHOURRÓn y E. BulYGIN: Normative Systems ${ }^{15}$, que ha ejercido y sigue ejerciendo gran influencia, especialmente en el mundo de habla hispana. La concepción de estos autores puede situarse en una línea equiparable a la de HART, aunque ellos, a diferencia de este último, no hacen profesión de fe expresa en el positivismo jurídico (al menos, no en Normative Systems). De hecho, criticaron de forma aguda y convincente la doctrina del viejo positivismo legalista, todavía defendida por KELSEN; una doctrina que negaba la existencia de lagunas basándose en la errónea o ambigua idea de que lo no prohibido debe considerarse permitido por el Derecho. Igualmente rechazaron el dogma de la plenitud hermética del Derecho, por considerarlo mera ilusión puesta al servicio de objetivos ideológico-políticos. En realidad, más que descartar del todo ese postulado básicamente positivista, lo reformularon en términos más aceptables, presentándolo como un ideal puramente científico que solo expresa la razonable exigencia de que los sistemas jurídicos sean completos ${ }^{16}$.

Lo anterior sugiere que, como HART, ALCHOURRÓN y BULYGIN tratan de elaborar una teoría puramente descriptiva y no valorativa de su objeto de estudio, en este caso las lagunas del Derecho, excluyendo del sistema jurídico cualquier valoración externa que lo ponga en relación necesaria con la moral. También como aquel, reconocen lo inevi-

13 A. CaTAnia, Il problema del diritto e l'obbligatorietà, Napoli, Ed. Scientifiche It., 1983, observa que el positivismo jurídico no había aceptado nunca la discrecionalidad judicial. También N. BobBIO, Il positivismo giuridico, Torino, Giappichelli, 1979, 244, afirma que uno de los presupuestos fundamentales del positivismo jurídico es que el juez no puede crear Derecho. KELSEN, sin embargo, pese a negar la existencia de lagunas en el Derecho, reconoce un amplio margen de discrecionalidad judicial.

${ }_{14}$ Cfr. N. BobBIo, Iusnaturalismo y positivismo jurídico, Madrid, Trotta, 2015, 105 y ss.

15 Op. cit., nota 6.

16 Cfr. C. Alchourrón y E. Bulygin, Introducción a la metodología..., op. cit., 25. Cuando aluden expresamente al positivismo jurídico en esa obra (pp. 240-241) tienen en mente el legalismo del siglo XIX, frente al que toman clara distancia. En cuanto a la versión del positivismo como actitud no valorativa en la concepción del Derecho, en Normative Systems no se encuentran pronunciamientos expresos sobre el problema clave de la relación entre Derecho y moral, aunque sí implícitos, puesto que sus autores asumen implícitamente la idea positivista de que el punto de vista moral es un punto de vista externo respecto al Derecho positivo. Expresamente afirman que las normas jurídicas positivas son convencionales (p. 234); aunque con limitaciones, porque de hecho al sistema jurídico se le suele exigir la satisfacción de algún ideal de justicia (p. 235). La inclinación hacia el positivismo jurídico, dudosa o ambigua en Normative Systems, se hace ya inequívoca en la obra posterior de E. BuLYGIN. 
table del recurso a la creación judicial de Derecho para resolver un problema, el de las lagunas, que pone en cuestión la concepción del orden jurídico como un verdadero sistema normativo. Sin embargo, a diferencia de HART, no reducen el fenómeno de las lagunas a las indeterminaciones derivadas de la textura abierta del lenguaje abstracto de las normas jurídicas. Para ellos, tales indeterminaciones no son propiamente lagunas, o si lo son deben distinguirse claramente de las lagunas normativas, típicas del Derecho ${ }^{17}$. Vamos a dedicar el resto del trabajo a examinar críticamente su concepción de las lagunas, valorando sobre todo la solidez de la misma como concepción básicamente positivista, en un contexto, el actual, en el que el positivismo jurídico parece encontrarse en crisis.

\section{LA CONCEPCIÓN DE ALCHOURRÓN Y BULYGIN SOBRE LAS LAGUNAS Y SUS CLASES}

Como ya se ha dicho, en el tema de las lagunas del Derecho, ALCHOURRÓn y BulYGIN han realizado aportaciones valiosas y su trabajo se ha convertido en punto de referencia casi obligado para los tratadistas actuales. Una de sus muchas observaciones certeras es que los juristas solo suelen interesarse por las lagunas que afectan a determinados microsistemas, como una ley o un código; mientras que la preocupación por las lagunas del ordenamiento en su conjunto es característica de los iusfilósofos ${ }^{18}$. La idea puede entenderse como una explicación de la distinción tradicional entre lagunas de la ley, que siempre se han admitido, y lagunas del Derecho en su conjunto, cuya posibilidad se ha considerado con frecuencia discutible, y que quizá represente un problema mal planteado. No voy a examinar aquí en detalle el complejo pensamiento de AlCHOURRÓn y BULYGIN sobre el problema de las lagunas. Examinaré únicamente y de forma sumaria su concepto, clases y propuestas de solución.

Ellos sitúan el concepto de laguna en la encrucijada o interrelación de tres elementos, un universo de casos, un universo de soluciones y un sistema jurídico que imputa las soluciones a los casos. Si las soluciones previstas por las normas de un sistema jurídico no alcanzan a resolver todos los casos, diremos que ese sistema jurídico tiene lagunas. $\mathrm{O}$, en palabras de ALCHOURRÓN y BULYGIN, cuando un caso no encuentra solución en las normas de un sistema jurídico «se dirá que ese caso es una laguna» ${ }^{19}$.

Conviene advertir que nuestros autores distinguen entre casos genéricos y casos individuales ${ }^{20}$. Casos genéricos son los supuestos de hecho abstractos regulados o

17 Ibid., 64.

18 Cfr. C. Alchourrón y E. Bulygin, Introd. a la metodología..., op. cit., 23. En la 122, n. 13, añaden que eso es precisamente lo que hace estériles los análisis de los iusfilósofos en este tema.

19 Ibid., 41. Merece comentario esa identificación entre caso y laguna, que es peculiar de ALCHOURRÓN y BULYGIN, y que muchos otros autores han adoptado siguiendo su ejemplo. En realidad apenas es algo más que una cuestión de estilo, o de forma de expresarse, pero quizá no sea del todo precisa y convenga replanteársela. En puridad, una cosa son las lagunas y otra los casos. Los casos no son lagunas, aunque su solución no esté prevista. Un caso puede verse afectado por una laguna, puede estar inmerso en una laguna, puede poner de relieve la existencia de una laguna, pero si queremos expresarnos con propiedad, un caso no puede ser una laguna. La laguna es la carencia de solución, no es el caso carente de solución. La laguna es el vacío normativo, no el caso afectado por ese vacío. De hecho, los casos individuales afectados por una determinada laguna pueden ser muchos, y sin embargo los distintos casos no serán distintas lagunas, sino que estarán inmersos en la misma.

${ }^{20}$ Cfr. Introd. a la metodología..., op. cit., 51 y ss. 
no regulados por las normas de un sistema jurídico; mientras que casos individuales son los conflictos jurídicos reales, las manifestaciones concretas y empíricas de los supuestos de hecho abstractos. El caso genérico está constituido por una serie de propiedades o características identificadas por las normas jurídicas (si es que lo regulan). El caso individual es un conflicto de la vida real que presenta las propiedades características del caso genérico. Cuando un caso individual es subsumible en un caso genérico regulado por un sistema jurídico, será merecedor de la solución o consecuencia jurídica prevista para el caso genérico. Esta distinción es importante porque, en opinión de AlChOuRRón y Bulygin, el problema de las lagunas del Derecho se plantea en el nivel de los casos genéricos y no en el de los casos individuales ${ }^{21}$. Si existen lagunas en el Derecho no es, contrariamente a lo que suele afirmarse, porque el legislador no puede prever la infinita diversidad de casos individuales que la vida social puede llegar a plantear, sino porque no ofrece solución para determinados casos genéricos, o porque no ofrece solución para todas las posibles combinaciones de propiedades de los casos genéricos que él mismo ha seleccionado como relevantes al regularlos.

Puede ocurrir, por ejemplo, que un caso genérico jurídicamente relevante, como el de la gestación subrogada, no haya sido regulado por el Derecho. En tal caso existiría una laguna normativa. Puede ocurrir igualmente que la gestación subrogada esté regulada en un sistema jurídico, pero que este nada disponga sobre alguna cuestión relevante con arreglo a los propios criterios de relevancia manifestados por el legislador. También sería un supuesto de laguna normativa. ¿Pero qué ocurriría si se planteara ante los tribunales un caso individual de gestación subrogada que presentara cierta particularidad, característica o propiedad no relevante con arreglo a los criterios de relevancia seleccionados por el legislador, pero que sería digna de tomarse en consideración con arreglo a determinados criterios valorativos? Aquí no existiría una verdadera laguna normativa, para ALCHOURRÓn y BULYGIN, sino en todo caso una laguna axiológica. Con la distinción entre lagunas normativas, que son auténticas carencias de regulación del sistema jurídico, y lagunas axiológicas, que solo son carencias del sistema jurídico para quien adopte ciertos criterios valorativos, nuestros autores hacen viable una concepción positivista de las lagunas, porque permite excluir las valoraciones, morales o ético-políticas, del sistema jurídico, y no reconocer que forman parte inherente al mismo.

Para tratar de confirmar esta tesis vamos a profundizar algo más en la distinción clave entre lagunas normativas y lagunas axiológicas. En realidad no son los dos únicos tipos de lagunas identificados por ALCHOURRÓN y BULYGIN. Ellos apuntan al menos otros dos, que denominan lagunas de conocimiento y lagunas de reconocimiento. Existiría una laguna de conocimiento cuando no es posible determinar si un caso individual pertenece o no a un caso genérico, porque no se conocen bien las propiedades del hecho $^{22}$. No es posible determinar, por ejemplo, si la muerte de un ciclista es un homici-

21 Ibid., 59.

22 Ibid., 63. Debe advertirse que AlCHOURRÓn y BULYGIN son perfectamente conscientes de que este tipo de «lagunas» poco tiene que ver con las lagunas normativas del Derecho, que se suscitan al nivel de los casos genéricos. Las llamadas lagunas de conocimiento serían simples problemas empíricos que se producen en la aplicación de las normas a los casos individuales (p. 61). 
dio imprudente o un simple accidente del que nadie es responsable, porque no se sabe bien cómo se produjo. Este tipo de problemas no suele ser tratado por los estudiosos de las lagunas del Derecho, y no es sorprendente, porque se trata de lagunas pero no del Derecho. Es cierto que afectan al Derecho, y este trata de superarlas mediante pruebas, presunciones, etc., pero la carencia que representan no está en las normas jurídicas, sino en la fijación de los hechos que se juzgan. Aunque son lagunas relevantes «para» el Derecho, no son lagunas «del» Derecho.

Distinto es el caso de las lagunas de reconocimiento, aunque ALCHOURRÓn y BULYGIN también ponen en duda su cualidad de verdaderas lagunas. Las caracterizan como casos individuales en los cuales, por falta de precisión semántica de los conceptos que caracterizan a un caso genérico, no se sabe si pertenecen o no al caso genérico en cuestión. Denominar lagunas del Derecho a estas situaciones de penumbra supondría el uso de una terminología poco afortunada, que puede dar lugar a confusiones si no se distingue claramente entre indeterminaciones semánticas y verdaderas lagunas normativas. La diferencia estriba, según explican, en que en las indeterminaciones no se echa en falta norma alguna, sino una mayor precisión en la norma existente ${ }^{23}$. Esta deficiencia se debe a una limitación de la que adolece el lenguaje en general, y que HART, siguiendo a otros filósofos del lenguaje, denominó textura abierta.

ALCHOURRÓN y BULYGIN no profundizan mucho en el concepto de las lagunas de reconocimiento, coherentemente con su idea de que no son lagunas del Derecho en sentido estricto. Sin embargo creo que el tema merecería una reflexión más detenida. Es cierto que existen indeterminaciones en las normas jurídicas que sería impropio designar como lagunas. A esa categoría pertenecen, por ejemplo, las indeterminaciones derivadas de la posible oscuridad o ambigüedad del lenguaje normativo; o las que se producen cuando el legislador delega en el juez la concreción de una regulación, para que pueda ajustarse mejor a las circunstancias de cada caso. Pero no todos los casos de penumbra son así. En muchos de ellos, detrás de una aparente indeterminación puramente lingüística se esconde una insuficiencia de regulación por parte del legislador. Es decir, una auténtica laguna de la ley.

Pensemos en el archiconocido ejemplo de la norma que prohíbe la entrada de vehículos en los parques públicos. Como no sabemos si el término vehículo, por su carácter abstracto, incluye a las bicicletas o a los monopatines, no sabemos si a estos artefactos les afecta o no la prohibición. ¿Pero realmente radica el problema en el significado de la palabra «vehículo», o en que el caso genérico previsto por la norma presenta una selección de propiedades tan poco afinada que no es posible saber si muchos casos individuales son o no subsumibles en el caso genérico? ${ }^{24}$. En otras palabras, muchos de los problemas que parecen derivarse de la textura abierta del lenguaje, en realidad se derivan de la falta de regulación de ciertas propiedades relevantes de un

${ }^{23}$ Ibid., 63-65.

${ }^{24}$ Según explican C. AlCHOURRÓn y E. BuLYgin, Intr. a la metodología..., op. cit., 145, cuando el universo de casos no es muy fino, y esto ocurre cuando el número de propiedades que lo integran es escaso, pueden aparecer lagunas. R. DwORKIN, «La complétude du droit», en P. AMSELEK y Ch. GRZEGORCZYK (eds.), Controverses autour de l'ontologie du droit, Paris, PUF, 1989, 135, sugiere que la cuestión de si se puede circular en bicicleta en el parque a pesar de la ley que prohíbe el acceso a los vehículos no encierra un problema lingüístico sino valorativo, que se resuelve reflexionando sobre el fin de la ley, que seguramente sería evitar la contaminación y el ruido en el parque. 
caso genérico. Es decir, son problemas de lagunas normativas. Un indicio a favor de esta impresión puede extraerse del enfoque que suele recibir el problema de las lagunas del Derecho en el mundo anglosajón, donde tiende a identificarse con el problema de la textura abierta del lenguaje. Si allí no se necesita recurrir al concepto de laguna normativa es porque el concepto de indeterminación lingüística puede ser más amplio de lo que suponen ALCHOURRÓN y BULYGIN.

Centrémonos ahora en la distinción entre lagunas normativas y lagunas axiológicas. Como veremos, solo las primeras son verdaderas lagunas del Derecho realmente existente. Las segundas son lagunas únicamente si se confronta el Derecho tal y como es con el Derecho tal y como debería ser (según los criterios valorativos adoptados por algún intérprete). Es decir, las lagunas axiológicas, tal y como las conciben ALCHOURRÓN y BULYGIN, no son verdaderas lagunas del Derecho, sino expresión de valoraciones sobre aquello que el Derecho debería regular y no regula.

Como buenos especialistas en lógica, AlCHOURRÓN y BULYGIN definen el concepto de laguna normativa en los siguientes términos: $x$ es una laguna normativa de $\alpha$ en relación a UCi y USmaxj si, y solo si, $x$ es un elemento de $U C i$ y no pertenece al dominio de $R(\alpha, U C i, U S \max j)^{25}$. Dicho llanamente: existe laguna normativa cuando un caso relevante jurídicamente no encuentra solución en las normas de un sistema jurídico. La clave del concepto está en la idea de relevancia jurídica. ¿Cómo distinguir qué es relevante en un sistema jurídico, de manera que su falta de regulación constituye una laguna, y qué no es relevante y por tanto pertenece al espacio vacío de Derecho (allí donde se sitúa todo aquello que el sistema jurídico no regula ni pretende regular)? Para responder a esta pregunta, conviene introducir una distinción que tiene un papel muy importante en la concepción de las lagunas de ALCHOURRÓN y BULYGIN. La distinción entre tesis de relevancia e hipótesis de relevancia.

La tesis de relevancia es la descripción de todas aquellas propiedades o características de casos que el sistema jurídico ha seleccionado como merecedoras de su regulación. En otras palabras, la tesis de relevancia establece descriptivamente los criterios de lo que el Derecho existente pretende regular. Una hipótesis de relevancia, por su parte, es una prescripción de propiedades que deberían considerarse relevantes jurídicamente con arreglo a determinados criterios valorativos ${ }^{26}$. Esos criterios valorativos pueden ser puramente subjetivos y expresar las preferencias personales del intérprete, pero también pueden ser objetivos, y expresar convicciones ético-políticas socialmente compartidas o principios de justicia universalmente válidos. Cuando las normas no solucionan casos, o no regulan propiedades de casos, que son relevantes con arreglo a la tesis de relevancia de un sistema jurídico, estaremos ante verdaderas lagunas normativas de ese sistema jurídico. Cuando las normas no solucionan casos o propiedades que deberían considerarse relevantes con arreglo a alguna hipótesis de relevancia referida al sistema jurídico de que se trate (o a todo sistema jurídico), estaremos ante lagunas axiológicas.

25 Ibid., 101. J. L. RoDRíGuEZ, Lógica de los sistemas jurídicos, Madrid, CEPC, 2002, 65, ofrece una definición más clara. Dice que un caso $C i$ de un universo de casos $U C j$ es una laguna del sistema normativo $\alpha$ con relación a un universo de soluciones si, y solo si, $\alpha$ no correlaciona $C i$ con ninguna solución de ese universo de soluciones.

${ }^{26}$ Cfr. C. Alchourrón y E. Bulygin, Intr. a la metod..., op. cit., 145 y ss. 
Otra diferencia destacada por ALCHOURRÓN y BULYGIN es que en las lagunas normativas el sistema jurídico no ofrece solución para determinados casos; mientras que en las lagunas axiológicas el sistema jurídico sí ofrece solución, pero es una solución insatisfactoria para el intérprete, porque este cree que debería considerarse relevante algún caso o propiedad al que el legislador no atribuye la relevancia que merece ${ }^{27}$. Como ya he anticipado, esta concepción de las lagunas axiológicas como desacuerdos valorativos con los criterios de relevancia del sistema jurídico las sitúa en el mundo de las especulaciones sobre lo que debería ser Derecho, y por tanto las excluye del Derecho realmente existente ${ }^{28}$.

\section{VALORACIÓN CRÍTICA DE LA CONCEPCIÓN POSITIVISTA DE LAS LAGUNAS DE ALCHOURRÓN Y BULYGIN}

La concepción expuesta en el apartado anterior, de forma inevitablemente simplificada, plantea diversos problemas. Voy a destacar solo los que afectan más claramente a su sesgo positivista. Los principales son tres: el primero consiste en la necesidad de reconocer que algunos criterios axiológicos (los que expresan los valores asumidos, y a veces declarados expresamente e impuestos por el propio legislador) forman parte de la tesis de relevancia del sistema jurídico. En consecuencia, debe admitirse que al menos algunas lagunas axiológicas son intrasistemáticas. Son lagunas del Derecho existente y no meras idealizaciones de un Derecho más completo. El segundo problema está relacionado con el anterior. Si la tesis de relevancia del sistema jurídico puede incluir criterios valorativos, no parece defendible la idea de que es posible determinar las lagunas normativas de forma puramente descriptiva y al margen de toda valoración. El tercer problema radica en la difícil justificación jurídica, al menos en los Estados de Derecho, de la discrecionalidad judicial como medio para colmar las lagunas.

En cuanto al primer problema, a diferencia de lo que ocurría en la época de Normative Systems, hoy pocos ponen en duda la existencia e importancia, en la mayor parte de los sistemas jurídicos actuales, de principios de justicia, valores morales y derechos fundamentales que, expresamente consagrados en la Constitución, forman parte importante del Derecho vigente y con frecuencia funcionan como criterios de validez

${ }^{27}$ Ibid., 158: «Para la existencia de una laguna axiológica es necesario que el caso tenga una solución. De lo contrario se trataría de una laguna normativa». Así como no deben confundirse las lagunas normativas con las axiológicas, tampoco se deben confundir las lagunas axiológicas, que suponen la no consideración como relevante de un caso o propiedad que debería ser relevante de acuerdo con cierto criterio axiológico, con los simples desacuerdos valorativos que se producen cuando las consecuencias jurídicas previstas por las normas se consideran injustas (pp. 158 y 161). Ciertamente, esos desacuerdos no suponen la existencia de lagunas. Si acaso podrían suponer la existencia de conflictos entre normas y principios o valores del Derecho.

28 D. Mendonca y R. A. Guibourg, La odisea constitucional. Constitución, teoría y método, Barcelona/ Madrid, Marcial Pons, 2004, 136 y 143, asumiendo el concepto de laguna axiológica de ALCHOURRÓN y BuLYGIN, suponen que con él se denuncia un procedimiento utilizado para cambiar subrepticiamente el sistema normativo, porque permite al intérprete excavar un hueco en el sistema jurídico para rellenarlo después con el material de su preferencia. Esta interpretación confirma que las lagunas axiológicas no son, en la concepción de AlCHOURRÓN y BULYGIN, verdaderas lagunas del sistema jurídico sino pretextos para modificarlo. En realidad, ellos no son tan drásticos. Reconocen que llamar lagunas a las axiológicas «no es del todo arbitrario», porque puede ser verdad que el legislador hubiera ofrecido una solución distinta a un caso que presenta una propiedad determinada, si la hubiera previsto (Introd. a la metod., 158). 
de las restantes normas jurídicas. Estos principios y valores, que integran un sistema de criterios axiológicos, constituyen la base, no ya de meras hipótesis de relevancia, sino de la tesis de relevancia del sistema jurídico. No es posible determinar qué es relevante jurídicamente en un ordenamiento sin tener en cuenta ese entramado de valoraciones. Con esto afirmamos que al menos algunas lagunas axiológicas, las que se derivan de los criterios valorativos del propio legislador, son auténticas lagunas del Derecho existente; no lagunas que el Derecho tendría si fuera como el intérprete cree que debería ser.

J. L. RODRíGUEZ, seguidor de ALCHOURRÓN y BULYGIN que ha profundizado en el estudio de las lagunas axiológicas, parece confirmar las conclusiones antes apuntadas, socavando quizá involuntariamente los cimientos de la concepción de sus maestros sobre las lagunas del Derecho. Reconoce que quien afirma la existencia de una laguna axiológica formulando una hipótesis de relevancia puede estar tratando, no ya de expresar sus propias valoraciones personales, sino de reconstruir el sistema axiológico presupuesto por el legislador. En otras palabras, afirmar que existe una laguna axiológica puede significar «no solamente que cierta propiedad debe ser considerada relevante en el sistema normativo $\alpha$ según un cierto sistema axiológico $\beta$, aun cuando no lo ha sido, sino además que el sistema axiológico $\beta$ coincide con el sistema axiológico del legislador» ${ }^{29}$. Lo anterior implica que «la hipótesis de relevancia tendrá carácter descriptivo» ${ }^{30}$, y eso es tanto como admitir que formará parte de la tesis de relevancia del sistema jurídico, porque determinará lo que «es» relevante, y no solo lo que debería ser considerado relevante.

Habría que distinguir, por tanto, dos tipos de lagunas axiológicas: las concebidas por ALCHOURRÓN y BULYGIN, a las que ya nos hemos referido, y las descritas por RODRÍGUEZ, que se producen cuando se presenta una determinada propiedad de un caso, irrelevante con arreglo al Derecho legislado, pero relevante con arreglo al sistema axiológico presupuesto (o proclamado en forma de valores y principios constitucionales) por el legislador. Lo peculiar de estas lagunas es que, a diferencia de las de ALCHOURRÓN y BULYGIN, no son lagunas extrasistemáticas que reflejan consideraciones valorativas ajenas al sistema jurídico sobre lo que debería considerarse jurídicamente relevante, sino que son lagunas intrasistemáticas, porque reflejan consideraciones valorativas que forman parte, implícita o expresamente, del Derecho ${ }^{31}$. No son lagunas imaginarias sino verdaderas lagunas del Derecho existente, al igual que las lagunas normativas. Lo que hace RODRíGUEZ, acertadamente a mi juicio, es reintroducir las lagunas axiológicas en el interior del Derecho, del que ALChOuRRÓn y BulYGin las habían expulsado ${ }^{32}$. Con ello reintroduce también en el Derecho el sistema axiológico

29 Cfr. J. L. RodRíGuez, Lógica de los sistemas jurídicos, op. cit., 75-76. «Toda autoridad normativa parte de un determinado sistema axiológico» (p. 75); sistema axiológico que se puede reconstruir a partir de las normas dictadas por dicha autoridad.

30 Ibid., 76. Cfr. también J. L. RoDRígueZ, «Lagunas axiológicas y relevancia normativa», en Doxa, vol. 22, $1999,357$.

31 Una idea similar maneja M. A. RoDILlA, Teoría del Derecho, op. cit., 346, al afirmar que la laguna axiológica se manifiesta cuando la aplicación de una norma a un caso produce resultados que colisionan con los principios informadores y fundamentadores de las leyes e instituciones del sistema jurídico.

32 Como observa F. ATRIA, «Sobre las lagunas», en Lagunas en el Derecho. Una controversia sobre el Derecho y la función judicial, Madrid/Barcelona, Marcial Pons, 2005, 23, las lagunas axiológicas, tal y como las conciben ALCHOURRÓN y BULYGIN, no son lagunas jurídicas de acuerdo con la tesis positivista de las fuentes sociales del Derecho, puesto que hay solución jurídica en esas fuentes. 
del legislador, y por consiguiente, la conexión necesaria entre el Derecho y la moral (al menos la moral del legislador), entreabriendo así la puerta a una concepción no positivista del Derecho.

El segundo problema que plantea la concepción de ALCHOURRÓN y BULYGIN afecta a la posibilidad de identificar las lagunas normativas de forma puramente descriptiva, prescindiendo de todo juicio de valor. Hemos visto que existe una laguna normativa cuando un caso o propiedad jurídicamente relevante no encuentra solución alguna en un determinado sistema jurídico. Si el caso fuera irrelevante pertenecería al espacio vacío de Derecho y no estaría afectado por una laguna del Derecho. Por tanto, la determinación de la relevancia es decisiva para la identificación de las lagunas. ¿Es posible decidir qué es relevante jurídicamente sin realizar ningún tipo de valoración? ${ }^{33}$. Ya el estudio de las lagunas axiológicas antes apuntado puso de relieve que la tesis de relevancia de cualquier sistema jurídico tiene que contar con el sistema axiológico del legislador, y por tanto, no puede estar libre de valoraciones que son inherentes al Derecho mismo.

A una conclusión similar llegó R. CARACCIOLO después de cuestionar la posibilidad, defendida por ALCHOURRÓN y BULYGIN, de una determinación objetiva, en el sentido de puramente descriptiva, y no prescriptiva o valorativa, de las lagunas. ¿Sería posible ofrecer una descripción libre de valoraciones de la relevancia jurídica de un caso no previsto por el Derecho? Los criterios utilizados tradicionalmente para determinar si un caso es relevante y, en consecuencia, debe ser regulado por el Derecho, nunca han estado libres de juicios de valor. El significado mismo del término «relevante» expresa ya una valoración y prefigura una prescripción de lo que debe regularse. ALCHOURRÓN y BULYGIN podrían alegar que es posible limitarse a describir las valoraciones de otras personas (las del legislador, en este caso) sin participar en ellas. Pero quien intenta determinar si un caso es relevante no puede limitarse a describir los criterios valorativos del legislador, sino que él mismo ha de asumir esos criterios para expresar un juicio de valor que se traduciría en el enunciado prescriptivo: «El caso $\mathrm{C}$ debe considerarse relevante en el sistema $\mathrm{S}$ y por tanto debe estar regulado». Si la determinación de las lagunas normativas obliga a realizar juicios de valor, concluye CARACCIOLO, la distinción entre lagunas normativas y axiológicas no puede ser tan nítida como la presentan AlCHOURRÓN y BULYGIN ${ }^{34}$.

33 F. ATRIA, «Sobre las lagunas», op. cit., 22, considera imposible diferenciar, sin argumentos valorativos, los casos que el Derecho no trata de regular y en los que el demandante carece de fundamento jurídico para litigar, de los casos afectados por lagunas normativas. También C. S. NinO, Algunos modelos metodológicos de ciencia jurídica, México, Fontamara, 1993, 72, cree que el concepto central de laguna es de índole valorativa: expresa la falta de solución normativa para un caso que debería tenerla. En la misma línea, C. W. CANARIS, «De la manière de constater et de combler les lacunes de la loi en droit allemand», en Le problème des lacunes en droit, loc. cit., 174, sostiene que la constatación de una laguna resulta de un juicio de valor, pero no puramente subjetivo sino expresivo de la valoración contenida en el orden jurídico. Se trata, pues, de un proceso teleológico (basado en la ratio legis o teleología inmanente en la ley) y no de lógica formal. Incluso A. Ross, Teoría de las fuentes del Derecho, trad. por J. L. MuÑoz DE B., A. DE PRADA y P. LóPEZ, Madrid, CEPC, 1999, 410, 414, reconoce que, antes de la aplicación del Derecho, solo es posible identificar la existencia de una laguna a partir de un criterio político o material, que consistiría en valorar si la aplicación formal de una ley contraviene o no un Derecho más profundo situado tras la ley.

34 Cfr. R. CARACCIOLO, «El concepto de "laguna”. Descripción o prescripción», en La noción de sistema en la teoría del Derecho, México, Fontamara, 1994, 27-36, donde ofrece sutiles argumentos para respaldar su tesis. Un sofisticado intento de rebatir la objeción de CARACCIOLO, tratando de demostrar que la noción de 
En efecto, la distinción entre lagunas normativas y lagunas axiológicas (intrasistemáticas) resulta borrosa, porque ambas presuponen operaciones valorativas. No es posible determinar qué casos o propiedades de casos son relevantes jurídicamente sin atender a los fines u objetivos que el legislador se propone conseguir con sus diferentes normas e instituciones, ni sin tener en cuenta los principios y valores que les dan sentido y justificación ${ }^{35}$. Conclusiones similares a esta, que identifican lo que es jurídicamente relevante por referencia a los fines y valores del Derecho, y en consecuencia conciben las lagunas normativas en términos axiológicos, son frecuentes en la doctrina tradicional. ALCHOURRÓN y BULYGIN critican la concepción de las lagunas de varios autores alemanes, como K. ENGISCH, K. LARENZ o J. ESSER, por caracterizarlas a partir de criterios valorativos, expresados en fórmulas vagas y vacuas, como la referencia al fin inmanente de la ley, a principios supralegales, a la idea del Derecho o a la naturaleza de las $\operatorname{cosas}^{36}$. Puede que no todas esas fórmulas sean igualmente afortunadas, pero todas apuntan a una realidad incuestionable que, no solo ALCHOURRÓN y BULYGIN, sino el positivismo jurídico en general, se resisten a aceptar. La realidad de que el Derecho persigue fines y se inspira en valores, y que esa carga teleológica y valorativa forma parte de su contenido, y es lo que permite, en primer lugar, detectar las lagunas del Derecho, y en segundo lugar, rellenarlas justificada y congruentemente.

Es cierto que en el Derecho existen lagunas que pueden detectarse sin realizar juicios de valor, y quizá sean estas las que tuvieron en mente ALCHOURRón y BULYGIN para definir su concepto de laguna normativa. Me refiero a las llamadas lagunas técnicas y a otras similares. Tales lagunas se manifiestan cuando no resulta posible la aplicación de una norma jurídica, porque carece de elementos imprescindibles para llevarla a cabo ${ }^{37}$. Si, por ejemplo, una ley que reforma el Código Penal tipifica como delito una conducta determinada, pero no especifica la pena correspondiente, no sería necesaria ninguna operación valorativa para detectar ahí una laguna. La evidencia de la laguna se desprende de la propia lógica interna de la regulación. Lo mismo ocurre cuando una ley no puede aplicarse porque requiere un desarrollo reglamentario que aún no se ha producido, o cuando el legislador olvida regular alguna combinación poco frecuente de propiedades que previamente ha fijado como relevantes. Pero estas lagunas, y en especial las conocidas como técnicas, no son las más significativas en el mundo del Derecho. Concebir las lagunas normativas, que en teoría deberían constituir el tipo central de lagunas del Derecho, como lagunas técnicas sería reduccionista $^{38}$. Sería una forma de eludir los problemas de verdadero interés que plantean las

\footnotetext{
laguna normativa no tiene por qué presuponer juicio de valor alguno, la realiza J. L. RODRíGUEZ, «Lagunas axiológicas y relevancia normativa», op. cit., 362-365.

35 Como convincentemente sostiene J. Ruiz Manero, «Algunas concepciones del Derecho y sus lagunas», en Lagunas en el Derecho. Una controversia sobre el Derecho y la función judicial, loc. cit., 123, las lagunas son déficits del sistema de reglas en relación con exigencias derivadas de los principios que las justifican.

${ }^{36} \mathrm{Cfr}$. C. AlChOURRón y E. BulYGin, Intr. a la metod..., op. cit., 61 y ss.

37 Vid. un análisis más detallado del concepto de laguna técnica en V. ItURRALDE SESMA, «Análisis de algunas cuestiones relativas al problema de las lagunas jurídicas», op. cit., 375 y ss. A. G. ConTE, Saggio sulla completezza degli ordinamenti giuridici, Torino, Giappichelli, 1962, 43, destaca la particularidad de las lagunas técnicas presentándolas como lagunas «en» el Derecho, y no lagunas «del» Derecho como las otras. La laguna técnica o teleológica, como CONTE la denomina, sería la laguna por antonomasia, porque imposibilita la acción del Derecho (p. 48).

38 Algo similar sostiene NiNO, Algunos modelos metodológicos de la ciencia jurídica, op. cit., 72, para quien el concepto descriptivo de laguna diseñado por $A \& B$ no es lo suficientemente amplio como para cumplir una
} 
lagunas del Derecho cuya detección obliga a realizar juicios de valor, reduciéndolas a la categoría de lagunas axiológicas, que en el pensamiento de ALCHOURRÓN y BULYGIN remiten a criterios valorativos externos al sistema jurídico ${ }^{39}$.

El tercer problema antes apuntado radica en el recurso a la discrecionalidad judicial como medio para colmar las lagunas del Derecho. En un principio, el positivismo jurídico, al menos el de la Europa continental, rechazaba la discrecionalidad judicial, pues aún formaba parte de su ideología la aversión de los pensadores ilustrados a la arbitrariedad de la que con frecuencia habían abusado los jueces en el Antiguo Régimen. Posteriormente, se generalizó la idea de que el reconocimiento de la discrecionalidad judicial formaba parte de las tesis centrales del positivismo jurídico ${ }^{40}$. Los comentaristas de la obra de ALCHOURRÓN y BULYGIN también suelen atribuirles la aceptación de la discrecionalidad judicial como inevitable remedio frente a las lagunas normativas.

Sin embargo, en Normative Systems las cosas no están tan claras en este punto. Ciertamente, allí se reconoce como una práctica judicial frecuente en los casos de lagunas la modificación del sistema jurídico mediante la creación de una nueva norma general ${ }^{41}$. Unas páginas más adelante, cuando ALCHOURRÓN y BULYGIN se plantean directamente la pregunta de cómo puede el juez fundamentar su decisión en caso de laguna, responden que habrá de modificar el sistema, pero para ello, observan, tendrá que estar autorizado; cosa que solo ocurre en algunas legislaciones, como ejemplifica el famoso art. 1 del CC suizo, que autoriza al juez para actuar como un legislador. Si al juez le está prohibido modificar el Derecho, entonces el problema es irresoluble. En todo caso, en Normative Systems, queda claramente apuntada la idea de que si el juez quiere decidir con arreglo a Derecho un caso de laguna, debe integrar el sistema jurídico creando una norma que colme la laguna y solucione el caso (genérico) ${ }^{42}$.

función importante en la actividad que los juristas realizan en el orden jurídico. «La completitud que interesa a los juristas es la completitud relativa a los casos que deben ser considerados relevantes».

39 Así ocurre, por ejemplo, en el caso de la flagrante laguna del antiguo Código Penal alemán en su regulación sobre el aborto, que no contemplaba el aborto por prescripción médica para salvar la vida de la madre. En opinión de ALCHOURRÓN y BULYGIN, no existía laguna normativa en ese caso, sino meramente axiológica, porque el Código contenía una regulación, pero tal regulación no se consideraba axiológicamente satisfactoria. Cfr. Introd. a la metodología..., op. cit., 162-163. En mi opinión, sería igualmente posible afirmar que el Código no regulaba el aborto terapéutico, un fenómeno sustancialmente distinto del aborto doloso y, por tanto, tenía una laguna que podría considerarse tanto axiológica como normativa. En general, nuestros autores conciben como lagunas axiológicas las llamadas lagunas secundarias o derivadas, es decir, aquellas que se manifiestan como consecuencia de cambios en la situación fáctica debidos, por ejemplo, al progreso técnico o al cambio de sensibilidad moral (cfr. 165-167) ¡Pero esas son precisamente las lagunas que más interesan a los juristas!

40 Cfr. H. L. A. HART, «El nuevo desafío al positivismo jurídico», trad. por L. HiERRO, F. LAPORTA y J. R. PÁRAMO, en Sistema, vol. 36, 1980, 5: «La tercera tesis positivista la llamaré la tesis de la discrecionalidad judicial. Sostiene que en todo sistema jurídico habrá siempre ciertos casos no previstos y no regulados legalmente [...] y, en consecuencia el Derecho es parcialmente indeterminado o incompleto. [...] Si el juez ha de llegar por sí mismo a una decisión en tales casos y no a inhibir su jurisdicción o (como BENTHAM defendía) remitir el asunto al legislativo, debe ejercitar su discrecionalidad y crear Derecho para el caso». E. BULYGIN, «Creación y aplicación del Derecho», en Lagunas en el Derecho..., loc. cit., 44, apoyándose precisamente en la autoridad de HART, afirma que la discrecionalidad judicial es uno de los pilares de la doctrina positivista.

${ }^{41}$ Cfr. Introd. a la metodología..., op. cit., 211 y 213 (n. 16).

${ }^{42}$ Ibid., 218, 222-223: «De hecho, los jueces tratan siempre de solucionar el caso genérico, ya sea por aplicación analógica o extensional de alguna norma existente, ya sea creando una nueva norma (procediendo como legislador)». 
En escritos posteriores, E. BULYGIN asume la discrecionalidad judicial de forma más inequívoca y decidida. En su opinión, el juez puede resolver discrecionalmente los conflictos jurídicos en caso de laguna. Ahora bien, para que su decisión no sea arbitraria debe apoyarse en una norma general que el propio juez habrá de crear previamente. Dicha norma reflejará la valoración del juez, pero esa valoración no tiene por qué expresar necesariamente sus preferencias personales. Puede expresar valoraciones socialmente compartidas o principios morales que el juez considere universalmente vá$\operatorname{lidos}^{43}$. Conviene advertir que lo anterior solo sería aplicable a las lagunas normativas, es decir, a los casos que carezcan de solución en el sistema jurídico. Pero si se presenta un caso afectado por una laguna axiológica, y por tanto existe una solución prevista en el sistema jurídico, por más que algunos la consideren insatisfactoria por no realizar ciertas distinciones que valoran como necesarias, lo que debe hacer el juez, a juicio de BULYGIN, es aplicar al caso la solución existente, pues las hipótesis de relevancia axiológica son externas al sistema jurídico y en el fondo meros subterfugios para burlar las exigencias del Derecho vigente ${ }^{44}$.

En mi opinión, ambas propuestas de solución son problemáticas. La segunda, la que afecta a las lagunas axiológicas, resulta insatisfactoria por insensible a unas demandas que pueden ser razonables y justificadas, especialmente si se fundan en los criterios axiológicos del legislador, en cuyo caso ignorarlas sería una obstrucción abiertamente antijurídica al hallazgo de una solución justa. La primera solución, la que apela a la discrecionalidad judicial para colmar las lagunas normativas es también profundamente antijurídica, por varias razones ${ }^{45}$. En primer lugar, porque supone la aplicación retroactiva de nuevas normas a casos que se produjeron previamente, cuando tales normas no existían. Se vulnera así el derecho que tiene cualquier persona a la seguridad jurídica de que se le apliquen las normas que él pudo conocer y a las que se atuvo, y no otras elaboradas ex post facto, que le impondrían deberes nuevos improvisados por el juez. En segundo lugar, porque vulnera uno de los principios básicos del Estado de Derecho, el de división de poderes, que atribuye la potestad de crear Derecho al poder legislativo, en representación del pueblo soberano que lo ha elegido, y no al poder judicial, que solo estaría legitimado para aplicar a los casos individuales

${ }^{43}$ Cfr. E. Bulygin, Introducción a Lagunas en el Derecho..., loc. cit., 12. En el mismo sentido se pronuncia en «Creación y aplicación del Derecho», op. cit., 35, 40 y ss.; «Los jueces ¿crean Derecho?», en J. MALEM (ed.), La función judicial, Barcelona, Gedisa, 2003, 32 y ss.; y «En defensa de El Dorado. Respuesta a F. Atria», en Lagunas en el Derecho..., loc. cit., 73 y ss. Resulta paradójico que BULYGIN sostenga la necesidad de la creación discrecional de una norma general por parte del juez para que su decisión del caso pueda basarse en ella y así no ser arbitraria. ¿Pero cómo no va a ser arbitraria una decisión basada en una norma creada arbitrariamente? Si se responde que la creación de esa norma no es arbitraria sino jurídicamente justificable, entonces no habrá existido creación sino hallazgo del Derecho aplicable, que por cierto es lo que debe hacer el juez para colmar las lagunas. Pero si se reconoce que la creación de la nueva norma no se puede justificar jurídicamente, sino solo prudencial o razonablemente, entonces no dejará de ser una norma jurídicamente arbitraria.

44 Ibid., 74-75.

${ }^{45}$ Como observa A. RóDENAs, Los intersticios del Derecho. Indeterminación, validez y positivismo jurídico, Madrid-Barcelona-Buenos Aires, Marcial Pons, 2012, 25, el recurso a la discrecionalidad judicial frente a las lagunas choca con la communis opinio de los juristas, que en los casos afectados por lagunas normativas exigen que las decisiones judiciales estén tan fundadas jurídicamente como en cualquier otro caso, y en los casos afectados por lagunas axiológicas tienden a pensar que puede tratarse de excepciones implícitas en las normas jurídicas, que las convertirían en derrotables. Un punto de vista similar defiende J. RUIZ MANERO, «Algunas concepciones del Derecho y sus lagunas», op. cit., 110 y ss. 
el Derecho previamente establecido por el legislador legítimo ${ }^{46}$. No parece la solución ideal, aunque podría ser impuesta por el legislador en algún sistema jurídico, que se autorice a los jueces para llenar las lagunas creando normas generales a partir de sus propias apreciaciones subjetivas, por muy sensatas que sean. No son las apreciaciones de los jueces las que deberían imponerse, sino las valoraciones socialmente compartidas, en las que el propio Derecho hunde sus raíces y en las que se encuentra su sentido y justificación.

Finalmente, es contrario a la racionalidad jurídica que se ignore la potencialidad del Derecho y de la argumentación para extraer respuestas justificadas a cualquier controversia jurídica a partir del complejo entramado de normas, valores y principios que integran el ordenamiento, sin necesidad de inventarlas discrecionalmente. Decían ALCHOURRÓN y BULYGIN en Normative Systems, criticando una idea de EsSER, que «si la existencia de las lagunas depende de la decisión de la voluntad, toda discusión racional del tema se hace imposible» ${ }^{47}$. Igualmente podría afirmarse, parafraseando lo anterior, que si la solución de las lagunas normativas depende de la decisión de la voluntad del juez, se hace imposible toda discusión racional de la jurisdicción, y de la naturaleza de Derecho en general.

\section{CONCLUSIONES}

1. El problema de las lagunas representa un desafío para el positivismo jurídico, porque amenaza la sostenibilidad de su concepción del Derecho como sistema cerrado de normas, autosuficiente y por tanto independiente de la moral o de valoraciones ético-políticas. Para defender esa concepción el positivismo jurídico adoptó una estrategia cambiante. Comenzó negando la existencia de lagunas, apoyándose en las doctrinas del espacio vacío de Derecho y de la norma de clausura, que hoy se consideran poco convincentes. Posteriormente admitió la posible existencia de indeterminaciones y lagunas, pero al confiar su compleción a la discrecionalidad judicial evitó reconocer la necesaria apertura del Derecho a otros sistemas normativos.

2. En esa segunda actitud cabe situar la posición de ALCHOURRÓn y BULYGIN, quienes admiten la existencia de lagunas, aunque de forma un tanto restrictiva, porque excluyen del sistema jurídico las lagunas axiológicas, como expresión de meras hipótesis de relevancia asumidas por los intérpretes; y además reducen a la categoría de axiológicas todas aquellas lagunas cuya detección obliga a realizar valoraciones (que son la mayoría). El intento de mantener las valoraciones, especialmente morales, fuera del Derecho positivo fracasa porque una de las posibles hipótesis de relevancia es la que expresa el sistema axiológico del legislador, inmanente en el sistema jurídico. Esa hipótesis de relevancia inherente al Derecho, basada en sus fines, principios y valores, declarados o implícitos, tendrá que formar parte de la tesis de relevancia, resultando así insostenible la distinción entre lagunas normativas y lagunas axiológicas intrasistemáticas, que serán en todo caso auténticas lagunas del Derecho.

46 Estos argumentos y otros similares fueron apuntados por R. DwORKIN en diversos lugares de su obra. Vid., por ejemplo, «Los casos difíciles», en Los derechos en serio, trad. por M. GuASTAVINO, Barcelona, Ariel, 1984,150 y ss.

47 Cfr. Introd. a la metodología, op. cit., 164 
3. Las lagunas, que son en su mayoría fenómenos relativos a determinados fines o valores inmanentes al Derecho, y que por tanto tienen un componente axiológico difícil de soslayar, obligan a reconocer la apertura del Derecho, al menos a un sistema axiológico determinado, el del legislador, que coincidirá normalmente con la moral socialmente dominante, cuya conexión con el Derecho quedaría así evidenciada.

4. Una forma de evitar esta conclusión abiertamente no positivista consiste en remitir la solución del problema de las lagunas, no al sistema axiológico inherente al Derecho, sino a la discrecionalidad judicial. Es una solución posible pero implausible, por incongruente con el propio sentido de la función jurisdiccional. Autorizar a un juez a decidir casos discrecionalmente es tanto como inducirle a abdicar de su papel institucional como aplicador y no creador del Derecho. Especialmente si se tiene en cuenta que el Derecho ofrece siempre, si no una orientación inequívoca, sí múltiples indicaciones en forma de fines, principios, valores, etc., capaces de guiar su decisión. Naturalmente, el juez hará bien en ejercer su discreción y buen juicio en el cumplimiento de sus obligaciones, pero si puede (y siempre puede) escoger entre una racionalidad extrajurídica, orientada por máximas prudenciales o preferencias personales, y una racionalidad jurídica orientada, aunque de forma difusa, por las razones subyacentes del Derecho, lo congruente con su deber institucional como aplicador del Derecho, es inclinarse por esta última. Si, como hemos defendido, la existencia de la mayor parte de las lagunas es relativa a ciertos fines, principios o valores del Derecho ¿no será lo más apropiado y congruente que sean esos mismos elementos inherentes al Derecho los que orienten la solución de los casos afectados por ellas? 